\title{
Quality of provider-client interaction in a reproductive health clinic in Isabela, Philippines
}

\author{
Rosalinda S. Guingab, Pedrita N. Medrano \\ Isabela State University, Echague, Isabela, Philippines
}

\begin{tabular}{l}
\hline \hline Article Info \\
\hline Article history: \\
Received Jan 16, 2021 \\
Revised May 20, 2021 \\
Accepted Jun 19, 2021 \\
\hline
\end{tabular}

\section{Keywords:}

Antenatal care

Clinic

Communication

Interface

Pregnant women

\begin{abstract}
The quality of provider-interaction determines client satisfaction and decision to seek health care. This research aimed to determine the women clients' perception of their quality of interaction with the health care providers in a government reproductive health clinic in one of the municipalities in northern Philippines. Respondents consisted of 30 pregnant women who had visited the clinic for prenatal health care check-up were interviewed. A structured questionnaire and a semi-structured guided for probing served as the study's research instruments. Women perceived the health care providers to possess good communication skills, and had displayed behavior that showed a regard for them. However, the providerinteraction was considered to be unilinear, with the provider perceived to have dominated the interface, The women also perceived only a somewhat evident show of sympathy/empathy. Hostile words were heard frequently. Creation of a two-way interaction with respect for their clients must be considered by the health care providers. Policies must also be formulated to improve the quality of provider-client interaction inside reproductive health clinics.
\end{abstract}

This is an open access article under the $\underline{C C B Y-S A}$ license.

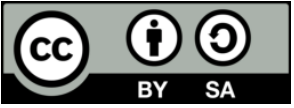

\section{Corresponding Author:}

Rosalinda S. Guingab

Isabela State University

San Fabian, Echague, Isabela 3309, Philippines

Email: rozsg@hotmail.com

\section{INTRODUCTION}

The World Health Organization data noted that about 810 women died each day in 2017 because of pregnancy and childbirth-related causes [1] with the greater number occurring in developing countries [2]. Estimates from the UN note that in 2008, approximately 18,000 from an estimated 350, 000 women dying of pregnancy-related causes were in Southeast Asia [3]. The Philippines is experiencing high maternal rate of 230 for every 100,000 live births, in contrast to its neighboring countries such as Thailand with only 110, Malaysia with 62 and Singapore with mere 14 [4]. Despite reported declines in maternal deaths in most of Southeast Asia, a faltering decline in mortality rates in the Philippines has also been noted [3]. Most of these maternal deaths could be prevented, according to the WHO, but this requires changes in the provision of maternity health care services [2], [5], and recognition of the necessity of quality health care in reproductive or family planning (FP) clinics. Women's access to and use of these services are essential in the improvement of health outcomes in low and middle income countries [6]. Quality of care (QOC) is an essential and critical input to family planning and reproductive health programs all over the world. Judith Bruce and Anrudh Jain, who developed the Bruce and Jain framework for reproductive health defined quality of care as "the way individuals and clients are treated by the system providing services" [7]. Disrespect of women seeking 
maternity care is becoming an urgent problem and creating a growing community of concern that spans the domains of healthcare research, quality, and education; human rights; and civil rights advocacy [8].

Health care quality, considered as patient judgment concerning overall service excellence in the hospital [9], particularly the interaction of providers and patients is a precursor of patients' satisfaction but is an area that seem to be neglected [10]. Women's satisfaction with the services they receive is regarded as an important factor in the utilization of reproductive health services [11]-[13]. Findings of a systematic review found that health care provider' behaviours and manner of interacting influenced women's health care seeking and their satisfaction with the reproductive health services [14]. In developing countries, women clients' perception regarding health services seems to be ignored by the providers [15]. Perceived satisfaction of clients including attitude of providers is a significant input in the decision of a person to seek health care [10], [11], [16], [17]. A major factor in the non-utilization of health services is the clients' perception of poor quality of these services [18].

A major factor in establishing an effective doctor-patient relationship is the communication between the two [19]. This is important in the delivery of high-quality health care. Much patient dissatisfaction and many complaints are due to breakdown in the doctor-patient relationship. A longitudinal study in Nepal noted women's low ratings of public hospital concerning interpersonal aspects [20]. Similarly, the perceived low quality of interaction between provider and client were noted by women to be a reason for their dissatisfaction of the health care delivery in a study in Mozambique [21]. However, a study in Ethiopia assessing the satisfaction of women with public family planning health services yielded positive results, with women reporting high satisfaction [22]. Indeed, the voices of pregnant women seeking reproductive health care are important inputs in improving the quality of care provided by family planning and reproductive health programs. Their views on the quality of services received from health care providers may prove to be significant inputs in improving the overall quality of reproductive health care services.

In the Philippines, the gains the Family Planning Program of the Department of Health has achieved so far in reducing total fertility rate, and in minimizing maternal mortality cases at 121 deaths per 100,000 live births [1] have led to a realization that there is still more to be done. Lamentably, however, there is dearth of researches on the quality of the services provided, much less the quality of the interface between the provider and the client in reproductive health and family planning clinics in this country. A better understanding of women's experiences in these clinics may help guide program leaders in developing strategies for improving quality of care. Interrogating patients what they think how they feel about the health service they have received is an important step towards improving the quality of care [23]. Studying this area of health care may create improvements in the quality of health care services, by recognizing the perceptions of the women clients. This study, therefore aimed to find out the quality of the provider-client interface as perceived by women seeking prenatal health care services in a public reproductive health clinic in Isabela, Philippines and to assess their level of satisfaction regarding their interpersonal interaction with the health care providers.

\section{RESEARCH METHOD}

Mixed methods research design, a type of research which combines both qualitative and quantitative research methods to allow in-depth capturing of the phenomenon being studied, was employed in this study. It was undertaken in a public health center in Isabela, a northern province in the Philippines, among a homogeneous sample of thirty women, purposively selected, and seeking prenatal health care services. It was conducted from September 2015 to May, 2016. The first part of the study made use of a structured interview schedule to elicit perception of women clients regarding the quality of their interpersonal interaction with the health provider. Items used for the structured interview were based on the IPPF quality of care framework [8].

The second part of the study which asked about women's personal observation regarding the quality of services provided made use of open-ended questions. Probing was carried out whenever there were unclear responses from the women. Reframing of questions was also done in instances when the women hesitated to answer some questions. Similar methodology was used in another study [24]. Recruitment of respondents for this study had been problematic, because prenatal check-up in this clinic was scheduled only every Wednesday with usually just two or three women waiting for the lone physician. There were days when either there were no patients or the physician (health care provider) had another appointment. Hence, data collection for this study took longer than what was planned. The women were interviewed immediately after their check-up and consultation in an area within the clinic compound but outside the hearing range of other people. This method allowed the women to share their experiences with the service delivery in a nonthreatening setting that assures distance from the clinic staff. Prior to the interview, their consent to participate in the study was solicited. Descriptive statistics were used to analyze information elicited from the 
structured interview. To add to the plausibility of the findings, direct quotes of the women were also added to the analysis. The researcher's observations on women's reactions during the interview were also noted.

\section{RESULTS AND DISCUSSION}

\subsection{Socio-demographic characteristics of the women}

Most of the pregnant women-respondents were relatively at the prime of their reproductive years $(19-24,36.7 \%)$ with mean age of 27 . An equal number graduated in high school and entered college (33\%). Almost all were housewives (93.3\%), with husbands mostly working as construction workers $(40 \%)$ or engaging in different kinds of jobs (37\%) and earning a minimum daily wage of 200-300 Philippine pesos, equivalent to USD 4-6 (53.4\%). Most of these women were just starting to build a family, with slightly more than a third (33\%) having one child to take care of, while less than third was pregnant with their first child.

\subsection{Women' impressions and perceptions of the provider}

The results of this study revealed interesting results regarding women's impressions and perceptions of the health care provider attending to them when they sought health care services a shown in Table 1 . While most of them agreed that the HCPs assured the women of confidentiality of information and instructed the women to return for a follow up check-up, a closer inspection reveal that they were mostly on the disagree side on whether the health care provider (HCP) exhibited good communication and counseling skills (48.3\% disagree, $33.3 \%$ strongly disagree). They, too, mostly disagreed on whether they were treated with dignity and respect (48.3\% disagree, 1 strongly disagreed). When asked whether the provider used words/actions showing dominance, hostility, verbal aggressiveness and rejection, their responses bordered mostly on the agree side (3.3\% Strongly Agreed; 46.7\% Agreed). Only a very small number remained neutral about their perceptions on all items. This finding is important as it is related to clients' satisfaction on health care services received from the HCPs, as one study looking into the patient-provider communication positively noted [25]. An overwhelming agreement was elicited when asked whether the provider dominated the interaction. One woman's statement explains this observation: "You just say, "Yes" to avoid being looked down upon" (W3). Probing for validation of responses was undertaken to validate the women's responses. Asked further about the frequency of providers displaying acts showing hostility, dominance, and verbal aggressiveness while the women were being examined, there were more who responded "frequent" $(46.7 \%)$, $10 \%$ of women said, "very frequent", while $43.3 \%$ said there was "no mention of hostile words at all" as shown in Figure 1.

Table 1. Women's impressions and perceptions on the health care provider (HCP) $n=30$

\begin{tabular}{|c|c|c|c|c|c|c|c|c|c|c|}
\hline \multirow[t]{2}{*}{ Impressions on the provider } & \multicolumn{2}{|c|}{$\begin{array}{l}\text { Strongly } \\
\text { agree }\end{array}$} & \multicolumn{2}{|c|}{ Agree } & \multicolumn{2}{|c|}{ Neutral } & \multicolumn{2}{|c|}{ Disagree } & \multicolumn{2}{|c|}{$\begin{array}{l}\text { Strongly } \\
\text { disagree }\end{array}$} \\
\hline & $\mathrm{n}$ & $\%$ & $\mathrm{n}$ & $\%$ & $\mathrm{n}$ & $\%$ & $\mathrm{n}$ & $\%$ & $\mathrm{n}$ & $\%$ \\
\hline $\begin{array}{l}\text { HCP listens first to me and seems to exhibit good } \\
\text { communication/counseling skills }\end{array}$ & 2 & 6.7 & 11 & 36.7 & 3 & 10.0 & 13 & 48.3 & 1 & 3.3 \\
\hline $\mathrm{HCP}$ treats me with dignity and respect & 1 & 3.3 & 13 & 43.3 & 5 & 16.8 & 10 & 33.3 & 1 & 3.3 \\
\hline $\begin{array}{l}\text { HCP uses words or actions showing dominance, hostility, } \\
\text { verbal aggressiveness, rejection }\end{array}$ & 1 & 3.3 & 14 & 46.7 & 1 & 3.3 & 13 & 43.3 & 1 & 3.3 \\
\hline $\mathrm{HCP}$ assures me of confidentiality of information I share & 2 & 6.7 & 17 & 56.7 & 3 & 10.0 & 7 & 23.3 & 1 & 3.3 \\
\hline $\begin{array}{l}\text { HCP gives instructions to me on when to return for follow up } \\
\text { check-up }\end{array}$ & 2 & 6.7 & 17 & 56.7 & 3 & 10.0 & 7 & 23.3 & 1 & 3.3 \\
\hline $\begin{array}{l}\text { HCP dominates the interaction without clear regard whether I } \\
\text { understand him/her }\end{array}$ & 17 & 56.7 & 12 & 40.0 & 0 & - & 1 & 3.3 & 0 & 3.3 \\
\hline
\end{tabular}

Probed further about these impressions, the women were observed to be somewhat uncomfortable, with eyes looking for people that may be connected to the health center. The researchers had to assure them again and again that their individual responses were confidential and would not in any way be attributed to a single respondent. Some of their reactions were:

"They are not respectful of their patients, especially those who ask a lot." (W5)

"Most of the staff here are not cordial." (W22)

It must be noted that prenatal care encounter presents a unique window of opportunity for the development of quality patient-provider relationships that can improve women's overall health. Better patient- 
provider communication is a practical area of focus towards improving patient trust, and trust is an important component of patient-provider relationship [19], [26].

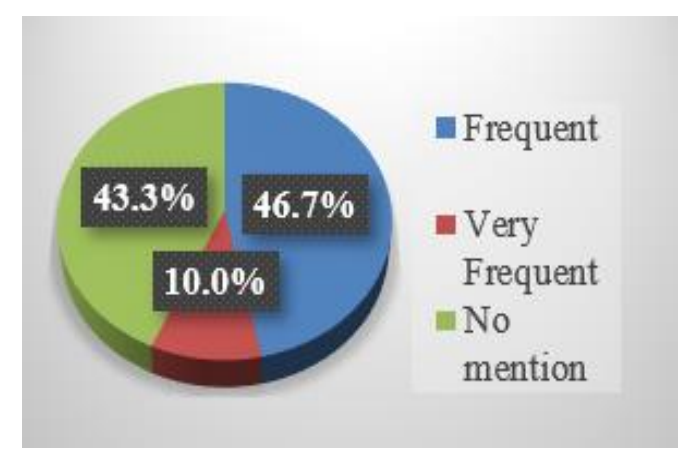

Figure 1. Perceived frequency of HCP's use of hostile words

\subsection{Women's impressions and perceptions of the quality of interaction inside the clinic}

Table 2 shows that more women had observed that the HCP preceded with the check-up and hardly asked the client about their pregnancy-related health concerns (53.3\% Disagreed). However, there were more who observed that the provider did not look down on them (36.7\% agreed; $43.3 \%$ Disagreed). This is a positive observation and worth applauding, even if the women perceived the interface to be one-way. As to whether the flow of discussion was unfocused and neither the provider nor the client seemed to be uninterested in the interaction, more women disagreed (40\%, Disagreed; 3\% Strongly Disagreed). Only an insignificant proportion neither agreed nor disagreed with regard to the items assessing their perception with the quality of interaction with the HCP. Similar observations were generated in another study with some participants going to private facilities reporting poor communication with healthcare providers [11].

Table 2. Women's impressions and perceptions of the quality of interaction inside the clinic $(\mathrm{n}=30)$

\begin{tabular}{|c|c|c|c|c|c|c|c|c|c|c|}
\hline \multirow[t]{3}{*}{ Impressions on the quality of interaction } & \multicolumn{10}{|c|}{ Reponses } \\
\hline & \multicolumn{2}{|c|}{$\begin{array}{l}\text { Strongly } \\
\text { agree }\end{array}$} & \multicolumn{2}{|c|}{ Agree } & \multicolumn{2}{|c|}{ Neutral } & \multicolumn{2}{|c|}{ Disagree } & \multicolumn{2}{|c|}{$\begin{array}{l}\text { Strongly } \\
\text { disagree }\end{array}$} \\
\hline & $\mathrm{n}$ & $\%$ & $\mathrm{n}$ & $\%$ & $\mathrm{n}$ & $\%$ & $\mathrm{n}$ & $\%$ & $\mathrm{n}$ & $\%$ \\
\hline $\begin{array}{l}\text { During the checkup, HCP proceeds with the checkup, hardly asks } \\
\text { me if I have questions; I am always in meek subservience }\end{array}$ & 1 & 3.3 & 16 & 53.3 & 5 & 16.7 & 5 & 16.7 & 3 & 10 \\
\hline HCP tends to look down on me & 2 & 6.7 & 11 & 36.7 & 1 & 3.3 & 13 & 43.3 & 3 & 10.0 \\
\hline HCP listens attentively to my concerns & 1 & 3.3 & 6 & 20.0 & 2 & 6.7 & 20 & 66.7 & 1 & 3.3 \\
\hline I speak out freely about my health concerns & 3 & 10.0 & 6 & 20.0 & 2 & 6.7 & 18 & 60.0 & 1 & 3.3 \\
\hline $\begin{array}{l}\text { Flow of discussion is unfocused and we } \\
\text { (I and the provider) are not really interested in the interaction }\end{array}$ & 6 & 20 & 7 & 23.3 & 2 & 6.7 & 12 & 40.0 & 3 & 10.0 \\
\hline
\end{tabular}

\subsection{Evidence of sympathy}

While four women told the interviewers that sympathy was very evident when they were inside the clinic, most (77\%) perceived only a somewhat evident display of empathy/sympathy on the part of healthcare providers, while three or $10 \%$ said there was no evidence of sympathy at all as shown in Figure 2. To quote two women "They don't listen." (W2) "When you say something, they issue a prescription right away." (W10) "They don't seem to care." (W16)

\subsection{Evidence of relaxed interaction}

In the same way that a bigger number of the respondents noted only a somewhat evident element of sympathy, even more $(83 \%)$ revealed only a somewhat evident relaxed interaction, while a small proportion $(7 \%)$ perceived it to be non-existent. Only three out of 30 women $(10 \%)$ had a positive perception, noting a very evident relaxed interaction with the provider at the clinic as shown in Figure 3. 


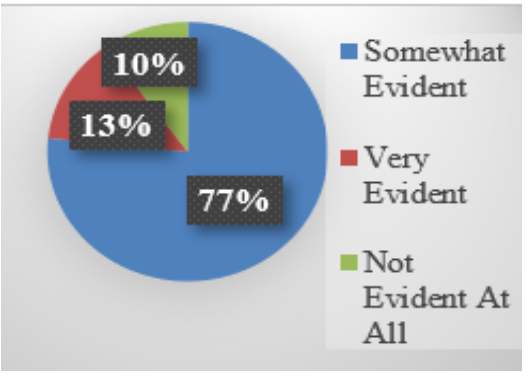

Figure 2. Evidence of sympathy

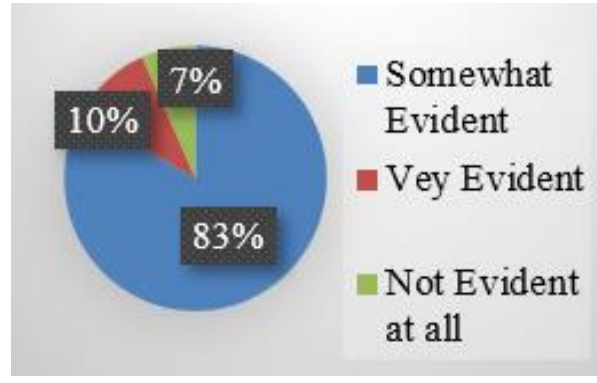

Figure 3. Evidence of relaxed interaction

\subsection{Level of satisfaction with the quality of care received/delivered}

Most of the pregnant women apparently wanted elucidation from the health providers examining them. Almost two-thirds (73\%) revealed they were dissatisfied with the amount of explanation given to them by the provider examining their condition as shown in Figure 4. Nevertheless, the women interviewed for this study were mostly satisfied with the quality of the examination/treatment they received. They were somehow ambivalent though with their satisfaction on the duration of consultation and were mostly $(53.3 \%)$ dissatisfied with their visual/auditory privacy during examination. Being women, they apparently still desired for their bodies not to be exposed from the prying eyes of other staff, except the provider attending to them, while being examined. Similar results were revealed in a health delivery service in Ghana [27]. Probed further about their general observation on the quality of services offered to them at the clinic, their varied responses include:

"Most often, I am not satisfied, because they only spend short time to examine us (W7). Sometimes, they would frown on us (W13). You would be lucky if the staff entertains you well." (W25)

These responses were elicited even from those who said they were satisfied with the quality of care delivered to them at the clinic.

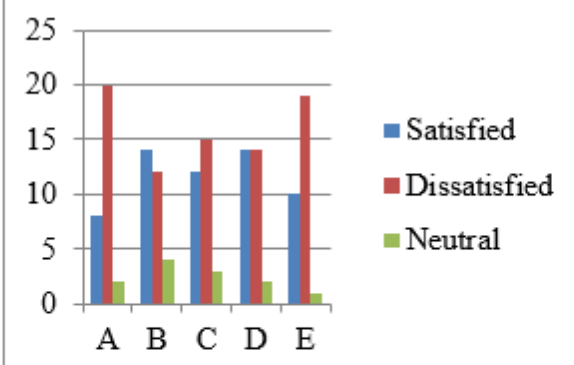
A- Amount of explanation given regarding the woman's concern
B- Quality of examination and treatment provided
C- Visual/auditory privacy during examination
D- Duration of consultation/Time spent with the HCP
E- Staff treatment of client

Figure 4. Clients' satisfaction with the quality of care received

Interestingly, findings of a study conducted in a facility in the Philippines showed that patients' level of satisfaction with the quality of care received was lower than the perceived level of satisfaction on the quality of health care delivered by nurses [28]. Findings of a study in Nigeria, likewise, found that only a few women indicated satisfaction with the services they received during pregnancy, delivery and after delivery care, with many women expressing dissatisfaction because of poor attitude of the health care staff [29] Similar observations were also found in a recent study in Ethiopia, in which almost half of the women interviewed indicated low level of patient satisfaction with maternal health care received in hospitals in Ethiopia [30]. 


\section{CONCLUSION}

Based on the findings of the study, the interface between the women clients and the health care provider at the reproductive heath clinic was mostly one-way, with the latter dominating the interaction at the clinic, and the former in meek subservience. There was initially observed reluctance to bring out to the open the women's impressions, but with prodding and probing, they willingly shared their observations which revealed only a somewhat evident show of empathy/sympathy for their concerns, somewhat evident relaxed interaction and providers' frequent use of hostile words. These experiences seem to point to a dismal quality of care that is worth further examining. Health care providers must consider creating an atmosphere of relaxed, two-way communication with element of respect as they interact with their patients. Policies to address the need to improve the quality of provider-client interaction in reproductive health clinics to make it more client-oriented must be formulated.

\section{ACKNOWLEDGMENTS}

The authors acknowledge the Isabela State University, Echague, Isabela, which financed this study, under its Gender and Development Program.

\section{REFERENCES}

[1] B. Gavira, M Albis, L. Bersales, and S. Romasoc, "Asia-Pacific Statistics Week A decade of action for the 2030 Agenda: Statistics that leaves no one and nowhere behind," 15-19 June 2020, Bangkok, Thailand. [Online]. Available:https://www.unescap.org/sites/default/files/11_Measuring_Maternal_Mortality_Using_Civil_Registratio n_Philippines.pdf

[2] World Health Organization, "Trends in maternal mortality: 1990 to 2015: Estimates by WHO, UNICEF, UNFPA, World Bank group and the United Nations population division," Geneva: World Health Organization, 2015.

[3] C. Acuin et al., "Maternal, neonatal, and child health in Southeast Asia: towards greater regional collaboration," Lancet, vol. 377, no. 9764, pp. 516-525, 2011, doi: 10.1016/S0140-6736(10)62049-1.

[4] UNFPA News, "Philippines: Maternal Mortality Rates Not Making Sufficient Progress to Meet MDGs," 7 April 2009. [Online]. Available: https://www.unfpa.org/news/philippines-maternal-mortality-rates-not-making-sufficient-progressmeet-mdgs

[5] World Health Organization, "Trends in maternal mortality 2000 to 2017 estimates by WHO, UNICEF, UNFPA, World Bank Group and the United Nations Population Division: Executive summary," World Health Organization, 2019.

[6] K. Ngugi et al., "Utilization of health services in a resource-limited rural area in Kenya: Prevalence and associated household-level factors," PLOS ONE, vol. 12, no. 2, pp. 1-12, 2017, doi: 10.1371/journal.pone.0172728.

[7] A. Galle, H. Vermandere, S Griffin, M. de Melo, L. Machaieie, D. VanBraeckel, and O. Degomme,"Quality of care in family planning services in rural Mozambique with a focus on long acting reversible contraceptives: a crosssectional survey,” BMC Womens Health, vol. 18, 2018, doi: 10.1186/s12905-018-0692-z.

[8] White Ribbon Alliance for Safe Motherhood, "Respectful maternity care: the universal rights of childbearing women," $2011 . \quad$ [Online]. Available: https://www.who.int/woman_child_accountability/ierg/reports/2012_01S_Respectful_Maternity_Care_Charter_Th e_Universal_Rights_of_Childbearing_Women.pdf

[9] N. Hidayat, Ahsan, A., M. Rahayu, and R. Lestari, "Response time, waiting time and service quality in emergency department," International Journal of Public Health Science, vol. 9, no. 3, pp. 199-204, 2020, doi: 10.11591/ijphs.v9i3.20435.

[10] I. Fatima, A. Humayun, M. Anwar, A. Iftikhar, M. Aslam, an M. Shafiq, "How Do Patients Perceive and Expect Quality of Surgery, Diagnostics, and Emergency Services in Tertiary Care Hospitals? An Evidence of Gap Analysis from Pakistan," Oman Medical Journal, vol. 32, no. 4, pp. 297-305, 2017, doi: 10.5001/omj.2017.58.

[11] R. Karim, M. Abdullah, A. Rahman, and A. Alam, "Identifying influence of perceived quality and satisfaction on the utilization status of the community clinic services: Bangladesh context," Bangladesh Med Res Counc Bull, vol. 41, no. 1, pp. 1-12, 2015.

[12] A. Dulla, M. Kondale, and G. Kejela, "Client Satisfaction with Family Planning Services and Associated Factors in the Rural Public Health Centers of Kucha District, Southern Ethiopia," Clinics Mother Child Health, vol. 16, no. 1, 2019, doi: 10.4172/2090-7214.1000312.

[13] Yelin et al., "Interactions between Patients, Providers, and Health Systems and Technical Quality of Care," Arthritis Care Res (Hoboken), vol. 67, no. 3, pp. 417-424, 2015, doi: 10.1002/acr.22427.

[14] P Mannava, K. Durrant, J Fisher. M Chersich and S. Luchters, "Attitudes and behaviours of maternal health care providers in interactions with clients: a systematic review," Globalization and Health, vol 11, no. 36, 2015, doi: 10.1186/s12992-015-0117-9.

[15] M Girma, C Robles, M Asrat, H Hagos, M G/slassie, and A Hagos, "Community Perception Regarding Maternity Service Provision in Public Health Institutions in 2018 and 2019: A Qualitative Study," Int J Womens Health., vol 12, pp 773-783, 2020, doi: 10.2147/IJWH.S250044. 
[16] F. Changee, A. Irajpour, M. Simbar, S. Akbari, "Client Satisfaction of Maternity Care in Lorestan province Iran," Iranian Journal of Nursing and Midwifery Research, vol. 20, no. 3, pp. 398-404, 2015.

[17] C. Okumu and B. Oyugi, "Clients' satisfaction with quality of childbirth services: A comparative study between public and private facilities in Limuru Sub-County, Kiambu, Kenya," PLoS ONE, vol. 13, no. 3, 2018, doi: 10.1371/journal.pone.0193593.

[18] T. Bagchi et al., "Non-utilization of public healthcare facilities during sickness: a national study in India," J. Public Health (Berl.), pp. 1-9, 2020, doi: 10.1007/s10389-020-01363-3.

[19] S. Chandra, M. Mohammadnezhad, P. Ward, "Trust and communication in a doctor-patient relationship: A literature review," J Healthc Commun, vol. 3 no. 3:36, pp. 1-6, 2018, doi: 10.4172/2472-1654.100146.

[20] R. Karkee, A. Lee, and P. Pokharel, "Women's perception of quality of maternity services: a longitudinal survey in Nepal," BMC Pregnancy and Childbirth, vol. 14, no. 45, pp. 2-7, 2014.

[21] L. Chavane, M. Dgedge, P. Bailey, O. Loquiha, M. Aerts, and M. Temmerman, "Assessing women's satisfaction with family planning services in Mozambique,” J. Fam. Plann. Reprod. Health Care, vol. 43, pp. 222-228, 2017, doi: 10.1136/jfprhc-2015-101190.

[22] W. Asrat, T. Mekonnen, and M. Bedimo, "Assessment of women's satisfaction with family planning service at public health facilities in Northwest Region of Ethiopia: a cross sectional study," Contraception and Reproductive Medicine, vol. 3, no. 25, pp. 1-8, 2018.

[23] D. Mesfin and T. Ginatmo, "Patient satisfaction and associated factors with services provided at outpatient departments," International Journal of Public Health Science, vol. 8, no. 4, pp. 406-412, 2019, doi: 10.11591/ijphs.v8i4.20375.

[24] T. Tancred, J. Schellenberg, T. Marchant, "Using mixed methods to evaluate perceived quality of care in southern Tanzania," International Journal for Quality in Health Care, vol. 28, no. 2, pp. 233-239, 2016, doi: 10.1093/intqhe/mzw002.

[25] N. Evans, "The Influences of Patient Provider Communication on the Adherence to Prenatal Care Recommendations among Pregnant Women," Dissertation. The University of Toledo, 2016.

[26] F Chipidza, R Wallwork, and T Stern, "Impact of the Doctor-Patient Relationship," Prim Care Companion CNS Disord.," vol 17, no. 5, 2015, doi: 10.4088/PCC.15f01840.

[27] K. Adjei et al., "Women's overall satisfaction with health facility delivery services in Ghana: a mixed-methods study," Trop Med Health, vol. 47, no. 41, 2019.

[28] E Benitez, R Giron, N Platon, "Client's satisfaction on nurses care delivery," LPU-Laguna Journal of Allied Medicine, vol. 3, no. 1, pp. 32-53, 2018.

[29] F. Okonofua et al., "Qualitative assessment of women's satisfaction with maternal health care in referral hospitals in Nigeria," Reprod Health, vol. 14, no. 44, pp. 1-8, 2017, doi: 10.1186/s12978-017-0305-6.

[30] Z. Weldearegay, S. Yehualahet, S. Sinkie, T. Debela, "Patient satisfaction and associated factors among in- patients in Primary Hospitals of North Shoa Zone, Amhara Regional State, Ethiopia," International Journal of Public Health Science, vol. 9, no. 2, pp. 76-81, 2020, doi: 10.11591/ijphs.v9i2.20412. 